\title{
Relationship between human disturbance and Endangered giant panda Ailuropoda melanoleuca habitat use in the Daxiangling Mountains
}

\author{
Cheng Zhao, Bisong Yue, Jianghong Ran, Timothy Moermond, Ning Hou \\ XUYU YANG and XiAODONG GU
}

\begin{abstract}
The Endangered giant panda Ailuropoda melanoleuca is one of the most threatened mammals. The species has experienced declines in its population and habitat as a result of human disturbance. We investigated the influence of human disturbance on habitat use by giant pandas in the Daxiangling Mountains, in China's Sichuan Province. We mapped all signs of giant panda and all locations of seven types of human disturbance in the study area. We used correlation analysis, generalized linear models, and Akaike information criteria to analyse the influence of the various types of human disturbances on habitat use by the giant panda. Our results showed that habitat use was positively correlated with elevation and distance from roads, residences, hydropower stations and logging or tree-felling sites, but negatively correlated with distance from bamboo shoot collection sites and trap sites. We found that the road-effect zone spanned a distance of c. 1,200 $\mathrm{m}$ and that human residence could affect the intensity of habitat use by giant pandas at distances $>2,500 \mathrm{~m}$. The effect of roads on habitat use was probably influenced by the association of roads with residences, hydropower stations and mines. In the area occupied by giant pandas, we recommend increased regulation to minimize the expansion and impact of roads, residences, hydropower stations and logging activities.
\end{abstract}

Keywords Ailuropoda melanoleuca, China, Daxiangling Mountains, Endangered, giant panda, human disturbance, protection

To view supplementary material for this article, please visit http://dx.doi.org/10.1017/So030605315000800

Cheng Zhao, Bisong Yue, Jianghong Ran (Corresponding author), Timothy MoERmond and Ning Hou Key Laboratory of Bio-resources and Eco-environment (Ministry of Education), and Sichuan Key Laboratory of Conservation Biology on Endangered Wildlife, College of Life Sciences, Sichuan University, Chengdu 610064, China. E-mail rjhong-01@163.com

XuYu Yang and Xiaodong Gu Sichuan Wildlife Resource Survey and Conservation Management Station, Chengdu, China

Received 20 December 2014. Revision requested 26 February 2015.

Accepted 26 June 2015. First published online 26 April 2016.

\section{Introduction}

The giant panda Ailuropoda melanoleuca is one of the 1 most threatened mammals and is categorized as Endangered on the IUCN Red List (Lu et al., 2008). The species was widely distributed in south-western China, including Hunan, Hubei, Sichuan, Shanxi, and Gansu Provinces, during the 16-19th centuries ( $\mathrm{Hu}, 2001)$, but as a result of extensive expansion of agriculture and transport systems and the widespread destruction and fragmentation of forest habitat, giant pandas are now confined to six fragmented mountain areas at the edge of the Tibetan Plateau (Fig. 1; $\mathrm{Hu}, 2001$; Ran et al., 2009). The smallest population is in the Daxiangling Mountains, where the species remains critically threatened by human disturbance (State Forestry Administration of China, 2006).

Understanding how various human activities affect pandas and their populations is critical for effective management and conservation of this charismatic species. Human activities are known to affect wildlife in many ways. Roads alter habitat and result in habitat loss and fragmentation, consequently reducing genetic exchange among populations (Way, 1977; Andrews, 1990; Carr et al., 2002; Zhu et al., 2010, 2011; Qi et al., 2012). Hunting or trapping can have a significant impact on local populations; for example, in Beichuan county c. 30 giant pandas were hunted each year before hunting of the species was prohibited by law in 1989 ( $\mathrm{Hu} \& \mathrm{Hu}, 2008)$. Logging leads to fragmentation and loss of forest habitat (Van Dyke et al., 1986).

Two types of disturbance effects over distance may be identified, one sharply defined by a threshold and the other characterized by a gradual influence over distance from the disturbance until some distance beyond which an effect cannot be detected (Eigenbrod et al., 2009). The effects of some types of disturbances are more pervasive than others, species may respond in various ways (Cuaron, 2000), and some disturbances may result in non-intuitive impacts, all of which makes it difficult to disentangle the individual effects of various types of disturbances, particularly as they may be occurring at the same time (Previtali et al., 2010). In the case of the giant panda the influence of various types of disturbances have been investigated individually ( $\mathrm{Li}$ et al., 2003; Ran et al., 2003; Bearer et al., 2008; Zeng et al., 2009; Gong et al., 2012) but it is difficult to develop an effective comprehensive protection plan for the species on this 


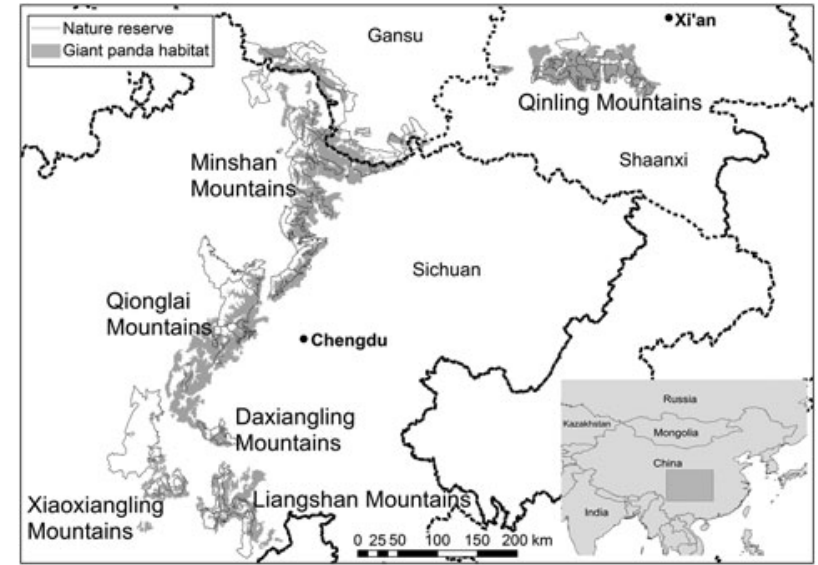

Fig. 1 Areas of suitable habitat for the giant panda Ailuropoda melanoleuca, and reserves established to protect the species in Sichuan, Gansu and Shaanxi provinces, China.

basis, as any reserve or protected area is likely to be affected by various disturbances at the same time.

To understand the influence of human disturbance on giant pandas more clearly and to assist managers to design more effective protection plans we studied the relationship between human disturbance and habitat use by giant pandas in the Daxiangling Mountains. Our goals were to determine which types of human disturbance have greater impacts on the habitat use of giant pandas; to study how the impacts of disturbance on habitat use vary with distance from a disturbance; and to improve protection plans for the giant panda based on greater understanding of the impacts of various types of human disturbances.

\section{Study area}

Fieldwork was carried out in the Daxiangling Mountains, which lie along a north-west-south-east axis in the southwest of the Sichuan Basin (Fig. 1). The highest peak is $3,552 \mathrm{~m}$. The climate is humid, annual rainfall is typically $1,300-2,000 \mathrm{~mm}$ and the mean annual temperature is c. $16^{\circ} \mathrm{C}$. Below $1,500 \mathrm{~m}$ elevation the vegetation is mainly broad-leaved forest, at $1,500-2,500 \mathrm{~m}$ it is mainly mixed forest, and $>2,500 \mathrm{~m}$ it is primarily coniferous forest $(\mathrm{Hu}$, 2001).

As giant pandas and their habitat mainly occur above $1,500 \mathrm{~m}(\mathrm{Hu}, 2001)$, the study area was initially defined as the area $>1,500 \mathrm{~m}$. To ensure our study area contained all potential habitat of the giant panda, it was expanded to include all areas within 3,00o m of giant panda sign (Fig. 2), as the diameter of the panda's home range is c. 3,000 $\mathrm{m} \mathrm{(Hu} \mathrm{\&}$ $\mathrm{Hu}, 2008)$. In the Daxiangling Mountains the main human disturbances are roads, residences, hydropower stations, logging, collection of bamboo shoots, trapping and mining (Supplementary Table S1; Hu, 2001; Ran et al., 2006; State Forestry Administration of China, 2006; Xu et al., 2006).

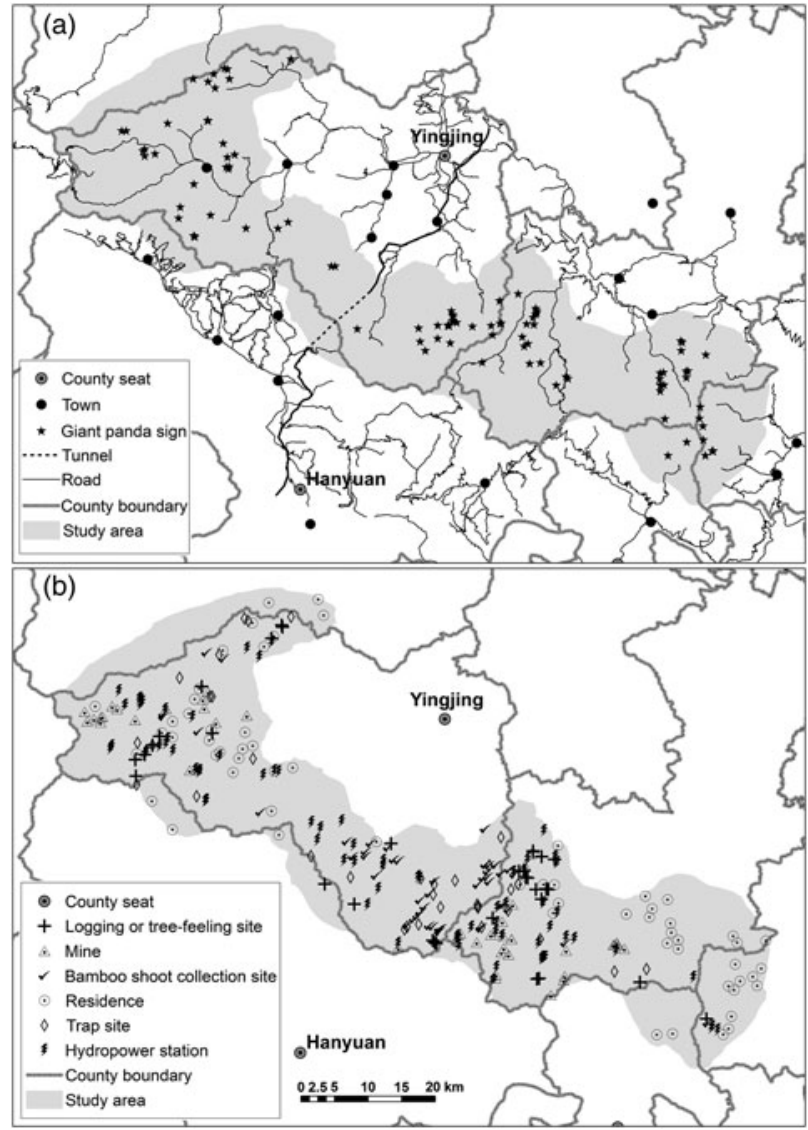

FIG. 2 (a) The locations of giant panda signs and roads and (b) human disturbance in the study area in the Daxiangling Mountains (Fig. 1), Sichuan, China.

\section{Methods}

The study area was surveyed by 30 investigators during May-September 2012. We divided the area into 688 $2-\mathrm{km}^{2}$ squares, and in each square investigators followed a transect of $>1.5 \mathrm{~km}$, searching for signs of giant pandas (e.g. faeces, signs of feeding), which were geographically referenced using a global positioning system (GPS). At each location where sign of giant panda was found, elevation, slope and slope aspect were recorded. GPS readings were also recorded at all locations of human disturbance (residences, mines, hydropower stations, logging and tree-felling sites, trap sites and bamboo shoot collection sites). The locations of all roads used by four-wheeled vehicles were obtained from government maps and Google Earth (Google Inc., Mountain View, USA; Fig. 2a; Supplementary Table $\mathrm{S}_{1}$ ). We treated the road system as one type of disturbance, as all of the roads within the study area had analogous characteristics (Supplementary Table S1). Our study was part of the 4 th national survey on the giant panda (Forestry Administration of China, unpubl. data).

We analysed the influence of human disturbance on habitat use by giant pandas in two stages. Firstly, we investigated which types of human disturbance have clearly 
detectable influences on the habitat use of giant pandas. Secondly, we investigated how the influence of the main types of disturbance on the intensity of habitat use by giant pandas varied as the distance from the disturbance increased.

We used kernel density analysis in ArcGIS v.10.o (ESRI, Redlands, USA) to calculate a density value for each sign of giant panda, which we used to represent the giant panda's activity intensity. This could also be treated as an index of habitat use intensity. For each giant panda sign we used distance analysis in ArcGIS to calculate the distance of the sign from the nearest road, residence, mine, hydropower station, bamboo shoot collection site, trap site, logging site or treefelling site.

We then used an information-theoretic approach to determine the main disturbance affecting the giant panda's activity intensity. We created 48 candidate generalized linear models (one null model, seven biogeography models, 20 disturbance models and 20 biogeography + disturbance models), with log link function. The distances from each type of human disturbance were used as independent variables and the giant panda's activity intensity was treated as a dependent variable in these models. Before variables were used in modelling a correlation analysis was conducted to identify multicollinearities among variables, some of which were then excluded from the analysis (Hosmer \& Lemeshow, 1989). The Akaike information criterion (AIC) was used for model selection, and the lowest AIC scores and highest Akaike weights were used to select the most parsimonious best-fit models (Anderson, 2008).

We hypothesized that human disturbance could affect habitat use intensity within a limited distance, within which range the influence on the giant panda decreased with increasing distance from the disturbance. Thus habitat use intensity may be expected to increase with increasing distance from a disturbance.

We used linear, logistic and exponential decay-fitting analyses to visualize the relationship between distance from human disturbance and habitat use intensity. We divided the study area into $2 \mathrm{~km}^{2}$ squares and established transects in each square such that the survey sites were distributed uniformly throughout the area. We calculated the habitat use intensity as $G H I_{i}^{x}=N_{i} / A_{i}$, where $\mathrm{GHI}_{i}$ is the habitat use intensity in region $i, N_{i}$ is the number of signs of giant panda in region $i, A_{i}$ is the area of region $i\left(\mathrm{~km}^{2}\right)$, and $x$ is the width of each region (we used $x=60,100$, $120,180,200,240,300,360,400$ and $500 \mathrm{~m}$ ).

\section{Results}

We recorded 131 locations of giant panda sign and 301 locations of human disturbance: 63 residences, 45 mines, 76 hydropower stations, 35 logging or tree-felling sites, 48 bamboo shoot collection sites and 34 trap sites (Fig. 2).

The activity intensity of giant pandas correlated positively with elevation and distance from logging or tree-felling sites, hydropower stations, residences and roads, and negatively with distance from bamboo shoot collection sites and trap sites (i.e. the habitat used by giant pandas was far from roads and residences but close to bamboo shoot collection sites and trap sites). There was also a positive correlation between distance from roads and distance to mines, hydropower stations and residences (Table 1 ).

We evaluated AIC values for 48 candidate models. The best model was the biogeography + disturbance model (Table 2), which gave a better fit than the biogeography and disturbance models individually. The best model included four variables: elevation, and distance from roads, bamboo shoot collection sites and trap sites (Table 2). The Akaike weights of the top three models were significantly larger than for other models (Table 2), indicating that the five variables in these top three models (elevation, and distance from roads, residences, bamboo shoot collection sites and trap sites) had the most significant influence on activity intensity.

In line- and curve-fitting analyses only two kinds of human disturbances (roads and residences) showed a good fit with panda habitat use intensity $\left(R^{2}>0.6\right.$; Fig. 3). We found that the logistic model and ExpDec1 model had better fits than the linear model (Fig. 3). Both the logistic and ExpDec models showed a significant decrease in habitat use intensity at distances $<1,200 \mathrm{~m}$ from roads. At distances $>1,200 \mathrm{~m}$ habitat use intensity appeared to be no longer influenced by roads. In Fig. 3 b all three types of models show good fits with habitat use intensity, and the curves show a continuous gradual change in slope. These curves suggest that residences have a strong but continuously declining influence on habitat use intensity to a distance of c. 2,500 m, beyond which the influence appears to be minimal.

\section{Discussion}

Both habitat and disturbance variables are important predictors of wildlife distribution and abundance (Morrison, 2001; Bhattarai \& Kindlmann, 2013). The habitat requirements of the giant panda have been studied comprehensively (e.g. Hu, 2001; Yu et al., 2003; Zeng et al., 2003; Ran et al., 2004; Liu et al., 2005; Yang et al., 2006; Gong \& Song, 2011; Qi et al., 2009; Kang et al., 2011; Zhang et al., 2011), and research on the influence of human disturbance is now important for protection of the species. Our results showed that three of four variables in the best generalized linear model were human disturbance variables (Table 2), indicating that human disturbance plays an important role in influencing the giant panda's activity index. Previous studies 


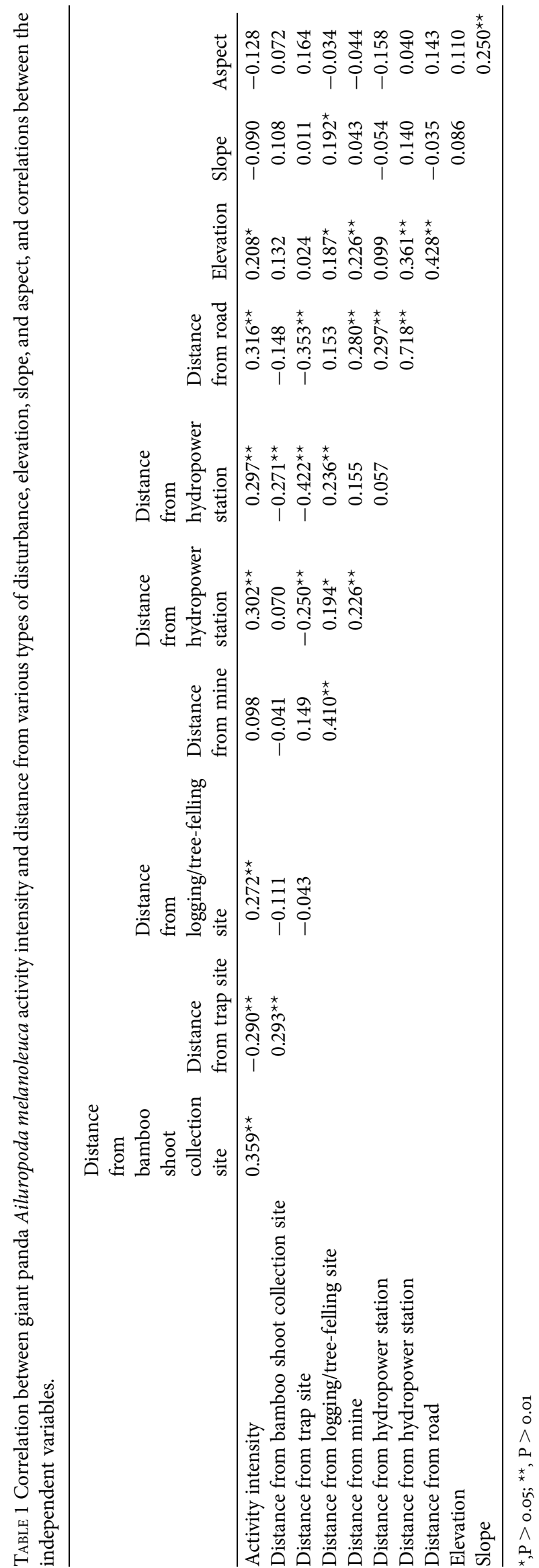

have found that roads have a significant influence on wildlife distribution (Kerley et al., 2002; Boarman \& Sazaki, 2006; Eigenbrod et al., 2009; Vanthomme et al., 2013), and we found that roads and residences have a strong influence on the habitat use of giant pandas (Table 2). As road building increases and residential areas expand, the distribution of the giant panda may become more isolated, which could affect the long-term survival of the panda population in the Daxiangling Mountains.

The correlation analysis showed a positive correlation between the giant panda's activity index and distance from roads, residences, mines, hydropower stations and logging sites (Table 1), which indicates that the giant panda avoided these disturbances. Distance to roads was also correlated with other fixed disturbances, which should be expected as residences, hydropower stations and mines are all connected by road. Disturbances caused by roads were therefore likely to be related to those caused by residences, hydropower stations and mines. Vanthomme et al. (2013) pointed out that roads could facilitate other human disturbances, as they are conduits for human activity and may also become barriers to wildlife movement (Forman \& Deblinger, 2000; Trombulak \& Frissell, 2000; Coffin, 2007). Thus, evaluating the influence of roads on the activity and distribution of giant pandas objectively and accurately may be critical to giant panda conservation.

Related research has indicated that the level of tolerable disturbance may show a threshold effect with distance (Huggett, 2005; Luck, 2005; Groffman et al., 2006), which could be used to predict the distribution of wildlife (Kostova \& Carlsen, 2005). In our research the relationship between habitat use intensity and distance from roads could be represented by a curve with either of two shapes (Fig. 3a). Despite the difficulty of determining where the inflection point occurs, the use of these curves could provide a logical model illustrating the effect of roads on habitat use intensity. The pattern of the response of habitat use intensity to roads effectively defines a road-effect zone. Such zones have been demonstrated for a variety of wildlife (Forman \& Deblinger, 2000; Boarman \& Sazaki, 2006; Semlitsch et al., 2007) but our study is the first to demonstrate a road-effect zone for habitat use by the giant panda. The extent of the road-effect zone is c. 1,200 $\mathrm{m}$, which exceeds the distances used in previous evaluations of giant panda habitat $(500$ or $720 \mathrm{~m}$; e.g. Liu et al., 1999; Xu et al., 2006; Shen et al., 2008; Li et al., 2010; Wu et al., 2010; Fan et al., 2011; Jian et al., 2012), and therefore the area of suitable habitat for giant pandas may have been previously overestimated. The influence of roads on giant pandas may, however, vary between mountain ranges, depending on the density of giant pandas and road disturbance (State Forestry Administration of China, 2006).

Although giant pandas appeared to avoid roads up to a threshold, there was no threshold in their response to 
TABLE 2 Summary of generalized linear models used to predict giant panda activity intensity, with the model variables, number of variables in each model (K), Akaike information criterion (AIC), difference in AIC between the model and the top model ( $\triangle$ AIC), and the Akaike weight of the ith model (Wi).

\begin{tabular}{|c|c|c|c|c|c|}
\hline Model & Variables & $\mathrm{K}$ & AIC & $\Delta \mathrm{AIC}$ & $\mathrm{Wi}^{*}$ \\
\hline Null & Intercept only & 0 & 548.085 & 56.728 & 0 \\
\hline \multirow[t]{5}{*}{ Biogeography } & Elevation, slope, aspect & 3 & 536.991 & 45.634 & 0 \\
\hline & Elevation & 1 & 533.324 & 41.967 & 0 \\
\hline & Elevation, slope & 2 & 535.226 & 43.869 & 0 \\
\hline & Slope, aspect & 2 & 552.078 & 60.721 & 0 \\
\hline & Elevation, aspect & 2 & 535.031 & 43.674 & 0 \\
\hline \multirow[t]{5}{*}{ Disturbance } & Distance from road, bamboo shoot collection site & 2 & 507.958 & 16.601 & 0 \\
\hline & Distance from road, trap site & 2 & 505.800 & 14.443 & 0 \\
\hline & Distance from road, mine, hydropower station & 3 & 515.807 & 24.45 & 0 \\
\hline & Distance from road, bamboo shoot collection site, trap site & 3 & 501.711 & 10.354 & 0.003 \\
\hline & Distance from residence, bamboo shoot collection site, trap site & 3 & 506.204 & 14.847 & 0 \\
\hline \multirow[t]{5}{*}{ Disturbance \& biogeography } & Elevation; distance from road, bamboo shoot collection site, trap site & 4 & 491.357 & 0 & 0.592 \\
\hline & Elevation; distance from residence, bamboo shoot collection site, trap site & 4 & 493.408 & 2.051 & 0.212 \\
\hline & Elevation; distance from bamboo shoot collection site, trap site & 3 & 493.635 & 2.278 & 0.189 \\
\hline & Elevation; slope; distance from road, logging or tree-felling sites & 4 & 503.716 & 12.359 & 0.001 \\
\hline & Slope; distance from road, bamboo shoot collection site, trap site & 4 & 503.636 & 12.279 & 0.001 \\
\hline
\end{tabular}

${ }^{\star}$ Represents the probability that the ith model is the best model in the candidate group
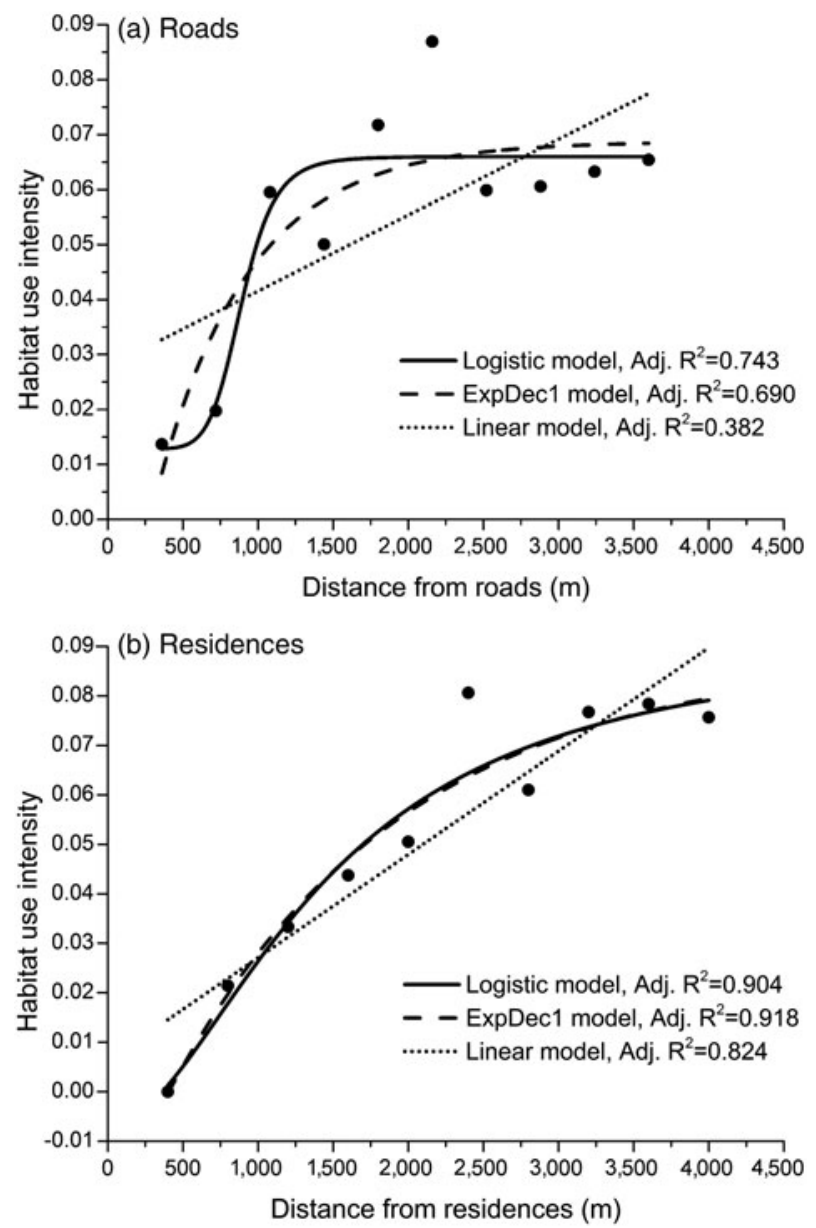

FIG. 3 Line- and curve-fitting analysis of the relationship between the giant panda's habitat use intensity and distance to (a) roads and (b) residences. residences; these findings reflect the response patterns reported by Eigenbrod et al. (2009). Other researchers have claimed, on an empirical basis, that disturbance by residences has no influence on giant panda habitat use at distances $>1,920 \mathrm{~m}$ (Liu et al., 1999; Xu et al., 2006; Wu et al., 2010; Jian et al., 2012) but our results show that residences can affect habitat use intensity even at distances up to $2,500 \mathrm{~m}$. Although the effect of residences on habitat use intensity is not the same as their effect on habitat, researchers should consider the influence of disturbance on both habitat and habitat use intensity when considering habitat quality.

We found that habitat use intensity was generally higher when pandas were closer to bamboo shoot collection sites and trap sites (Table 1). Why did the pandas not avoid these two types of disturbance? Their responses may have depended on whether a disturbance was fixed (e.g. roads, residences, mines, hydropower stations) or temporary (e.g. bamboo shoot collection, trapping). Human presence at the latter sites is likely to be less frequent, of shorter duration, and less intrusive. Regarding such non-fixed disturbances, Gill et al. (1996) pointed out that wildlife could return to utilize remaining resources after the disturbance. Wei et al. (1996) also found that although pandas retreated from sites where bamboo shoots were being collected, they returned to those sites after the collectors had gone. The same may be true of non-fixed human disturbances in our study area, and therefore bamboo shoot collection and trapping may have only limited effects on the distribution of giant pandas, with the extent of the influence varying according to the frequency, duration and intensity of such non-fixed disturbances. 
As all fixed disturbances are closely related to roads, roads may be the most significant source of disturbance to the giant panda. Thus management of roads, and controlling their expansion, is essential in areas of giant panda habitat, particularly within the road-effect zone. Residences are another significant disturbance to the giant panda, and therefore controlling the expansion and location of residences is imperative. The influence of other human disturbances on the giant panda should not be ignored. Bamboo shoot collection, hydropower construction and mining should be controlled to minimize their expansion into areas of undisturbed habitat, and logging and trapping should be prohibited. Our findings show that the type and location of human disturbance can determine their influence on giant panda habitat, and the potential impacts of multiple types of disturbances are complex and need to be considered. We have passed our findings to the appropriate authorities for use in informing conservation efforts for the giant panda.

\section{Acknowledgements}

We thank the fourth giant panda survey team of Sichuan Province. This study was supported by the Sichuan Forestry Department.

\section{References}

Anderson, D.R. (2008) Model Based Inference in the Life Sciences: A Primer on Evidence. Springer, New York, USA.

Andrews, A. (1990) Fragmentation of habitat by roads and utility corridors: a review. Australian Zoologist, 26, 130-141.

Bearer, S., Linderman, M., Huang, J.Y., An, L., He, G.M. \& Liu, J. G. (2008) Effects of fuelwood collection and timber harvesting on giant panda habitat use. Biological Conservation, 141, 385-393.

Bhattarai, B.P. \& Kindlmann, P. (2013) Effect of human disturbance on the prey of tiger in the Chitwan National Park: implications for park management. Journal of Environmental Management, 131, 343-350.

BOARMAN, W.I. \& SAZAKI, M. (2006) A highway's road-effect zone for desert tortoises (Gopherus agassizii). Journal of Arid Environments, 65, 94-101.

Carr, L.W., Fahrig, L. \& Pope, S.E. (2002) Impacts of landscape transformation by roads. In Applying Landscape Ecology in Biological Conservation (ed. K.J. Gutzwiller), pp. 225-243. Springer, New York, USA.

Coffin, A.W. (2007) From roadkill to road ecology: a review of the ecological effects of roads. Journal of Transport Geography, 15, 396406.

Cuaron, A.D. (2000) A global perspective on habitat disturbance and tropical rainforest mammals. Conservation Biology, 14, 1574-1579.

Eigenbrod, F., Hecnar, S.J. \& Fahrig, L. (2009) Quantifying the road-effect zone: threshold effects of a motorway on anuran populations in Ontario, Canada. Ecology and Society, 14, 1-18.

FAN, J.T., LI, J.S., QUAN, Z.J., WU, X.P., Hu, L.L. \& YANG, Q.P. (2011) Impact of road construction on giant panda's habitat and its carrying capacity in Qinling Mountains. Acta Ecologica Sinica, 31, $145-149$.
Forman, R.T.T. \& Deblinger, R.D. (200o) The ecological road-effect zone of a Massachusetts (U.S.A.) suburban highway. Conservation Biology, 14, 36-46.

Gill, J.A., Sutherland, W.J. \& Watkinson, A.R. (1996) A method to quantify the effects of human disturbance on animal populations. Journal of Applied Ecology, 33, 786-792.

Gong, M.H., Hou, M., Lin, C., Song, Y.L. \& OuYang, Z.Y. (2012) The quantitative assessing of trail impacts on giant panda activity based on field track points and GIS. Biodiversity Science, 20, 420426.

Gong, M.H. \& SonG, Y.L. (2011) Topographic habitat features preferred by the Endangered giant panda Ailuropoda melanoleuca: implications for reserve design and management. Oryx, 45, 252-257.

Groffman, P.M., Baron, J.S., Blett, T., Gold, A.J., Goodman, I., Gunderson, L.H. et al. (2006) Ecological thresholds: the key to successful environmental management or an important concept with no practical application? Ecosystems, 9, 1-13.

Hosmer, D.W. \& Lemeshow, S. (1989) Applied Logistic Regression. John Wiley and Sons, New York, USA.

Hu, J.C. (2001) Research on the Giant Panda. Shanghai Publishing House of Science and Technology, Shanghai, China. [In Chinese]

Hu, J.C. \& Hu, X. (2008) Trailing the Giant Panda. Jiangsu Publishing House of Science and Technology, Nanjing, China. [In Chinese]

Huggett, A.J. (2005) The concept and utility of 'ecological thresholds' in biodiversity conservation. Biological Conservation, 124, 301-310.

Jian, J., JiAng, H., Jiang, Z.S., Zhou, G.M., YU, S.Q., PenG, S.L. et al. (2012) Evaluating the habitat quality of giant panda (Ailuropoda melanoleuca) using habitat suitability index (HSI). Polish Journal of Ecology, 60, 827-837.

KAnG, D.W., KAnG, W., TAN, L.Y. \& Li, J.Q. (2011) The habitat selection of giant panda in Wanglang Nature Reserve, Sichuan province, China. Acta Ecologica Sinica, 31, 401-409. [In Chinese]

Kerley, L.L., Goodrich, J.M., Miquelle, D.G., Smirnov, E.N., Quigley, H.B. \& Hornocker, M.G. (2002) Effects of roads and human disturbance on Amur tigers. Conservation Biology, 16, 97-108.

Kostova, T. \& Carlsen, T. (2005) The effect of small-size habitat disturbances on population density and time to extinction of the prairie vole. Nonlinear Analysis: Real World Applications, 6, 731746.

LI, H.L., LI, D.H., LI, T., QIAO, Q., YANG, J. \& ZhanG, H.M. (2010) Application of least-cost path model to identify a giant panda dispersal corridor network after the Wenchuan earthquake-Case study of Wolong Nature Reserve in China. Ecological Modelling, 221, 944-952.

Li, Y.M., Guo, Z.W., YAnG, Q.S., WANG, Y.S. \& Niemela, J. (2003) The implications of poaching for giant panda conservation. Biological Conservation, 111, 125-136.

Liu, J.G., Ouyang, Z.Y., Taylor, W.W., Groop, R., Tan, Y.C. \& ZHANG, H.M. (1999) A framework for evaluating the effects of human factors on wildlife habitat: the case of giant pandas. Conservation Biology, 13, 1360-1370.

LiU, X.H., Toxopeus, A.G., Skidmore, A.K., Shao, X.M., Dang, G. D., WANG, T.J. \& Prins, H.H.T. (2005) Giant panda habitat selection in Foping Nature Reserve, China. The Journal of Wildlife Management, 69, 1623-1632.

Lu, Z., Wang, D. \& Garshelis, D.L. (IUCN SSC Bear Specialist Group) (2008) Ailuropoda melanoleuca. In The IUCN Red List of Threatened Species v. 2015.2. Http://www.iucnredlist.org [accessed 13 August 2015].

LuCK, G.W. (2005) An introduction to ecological thresholds. Biological Conservation, 124, 299-300.

Morrison, M.L. (2001) A proposed research emphasis to overcome the limits of wildlife-habitat relationship studies. The Journal of Wildlife Management, 65, 613-623. 
National Geomatics Center of China (2014) Http://ngcc.sbsm. gov.cn/article/en/ [accessed 21 August 2015].

Previtali, M.A., Lehmer, E.M., Pearce-Duvet, J.M.C., Jones, J.D., Clay, C.A., Wood, B.A. et al. (2010) Roles of human disturbance, precipitation, and a pathogen on the survival and reproductive probabilities of deer mice. Ecology, 91, 582-592.

QI, D.W., Hu, Y.B., Gu, X.D., Li, M. \& Wei, F.W. (2009) Ecological niche modeling of the sympatric giant and red pandas on a mountain-range scale. Biodiversity and Conservation, 18, 2127-2141. QI, D.W., Hu, Y.B., Gu, X.D., YanG, X.Y., YanG, G. \& Wei, F.W. (2012) Quantifying landscape linkages among giant panda subpopulations in regional scale conservation. Integrative Zoology, $7,165-174$.

Ran, J.H., Liu, S.Y., Wang, H.J., Sun, Z.Y., ZenG, Z.Y. \& LiU, S.C. (2003) Effect of grazing on giant pandas' habitat in Yele Nature Reserve. Acta Theriologica Sinica, 23, 288-294. [In Chinese]

Ran, J.H., LiU, S.Y., WanG, H.J., Zeng, Z.Y., Sun, Z.Y. \& LiU, S.C. (2004) A survey of disturbance of giant panda habitat in the Xiaoxiangling Mountains of Sichuan Province. Acta Theriologica Sinica, 24, 277-281. [In Chinese]

RAN, J.H., ZENG, Z.Y., LIU, S.C. \& WANG, H.J. (2006) A survey of the Giant Panda population and habitats in the Daxiangling Mountains. Journal of Sichuan University, 43, 889-893. [In Chinese]

RAN, J.H., DU, B.B. \& YUE, B.S. (2009) Conservation of the Endangered giant panda Ailuropoda melanoleuca in China: successes and challenges. Oryx, 43, 176-178.

Semlitsch, R.D., Ryan, T.J., Hamed, K., Chatfield, M., Drehman, B., Peка éк, N. et al. (2007) Salamander abundance along road edges and within abandoned logging roads in Appalachian forests. Conservation Biology, 21, 159-167.

Shen, G.Z., Feng, C.Y., Xie, Z.Q., Ouyang, Z.Y., Li, J.Q. \& Pascal, M. (2008) Proposed conservation landscape for giant pandas in the Minshan Mountains, China. Conservation Biology, 22, 1144-1153.

State Forestry Administration of China (2006) The 3 rd National Survey Report on Giant Panda in China. Science Press, Beijing, China. [In Chinese]

State Forestry Administration of China (2015) The results of 4rd National Survey. Http://www.forestry.gov.cn/main/72/ content-74288o.html [In Chinese]

Trombulak, S.C. \& Frissell, C.A. (2000) Review of ecological effects of roads on terrestrial and aquatic communities. Conservation Biology, 14, 18-30.

Van Dyke, F.G., Brocke, R.H., Shaw, H.G., Ackerman, B.B., Hemker, T.P. \& Lindzey, F.G. (1986) Reactions of mountain lions to logging and human activity. The Journal of Wildlife Management, 50, 95-102.

Vanthomme, H., Kolowski, J., Korte, L. \& Alonso, A. (2013) Distribution of a community of mammals in relation to roads and other human disturbances in Gabon, Central Africa. Conservation Biology, 27, 281-291.
WAY, J.M. (1977) Roadside verges and conservation in Britain: a review. Biological Conservation, 12, 65-74.

Wei, F.W., Zhou, C.Q., Hu, J.C., YANG, G. \& WANG, W. (1996) Giant panda's selection for bamboo resources in Mabian Dafengding Reserve. Acta Theriologica Sinica, 16, 171-175. [In Chinese]

Wu, P.F., Liv, X.H., ShaO, X.M., Zhu, Y. \& CAI, Q. (2010) GIS application in evaluating the potential habitat of giant pandas in Guanyinshan Nature Reserve, Shaanxi Province. Procedia Environmental Sciences, 2, 111-122.

Xu, W.H., Ouyang, Z.Y., Viña, A., Zheng, H., Liu, J.G. \& Xiao, Y. (2006) Designing a conservation plan for protecting the habitat for giant pandas in the Qionglai mountain range, China. Diversity and Distributions, 12, 610-619.

YanG, C.H., ZhanG, H.M., Zhou, X.P., Wang, P.Y. \& Wang, X.M. (2006) Review of habitat selection in the giant panda (Ailuropoda melanoleuca). Acta Ecologica Sinica, 26, 3442-3453. [In Chinese]

YU, G.Z., JIANG, Z.G., ZhaO, Z.L., WANG, B.F. \& WANG, Y. (2003) Feeding habitat of giant pandas (Ailuropoda melanoleuca): why do they prefer bamboo patch edges? Journal of Zoology, 261, 307-312.

Zeng, T., Ran, J.H., Liu, S.Y., Sun, Z.Y., Liu, S.C. \& Zeng, Z.Y. (2003) Habitat exploitation by panda in the Baihe Nature Reserve. Chinese Journal of Applied Environmental Biology, 9, 405-408. [In Chinese]

ZENG, Z.G., LI, J.S., YAN, W.B., FAN, J.T. \& SonG, Y.L. (2009) Impact of Lanzhou-Chongqing highway and railway on the movement of giant pandas and their habitat protection. Sichuan Journal of Zoology, 28, 641-646. [In Chinese]

Zhang, Z.J., Swaisgood, R.R., Zhang, S.N., Nordstrom, L.A., WANG, H.J., Gu, X.D. et al. (2011) Old-growth forest is what giant pandas really need. Biology Letters, 7, 403-406.

Zhu, L.F., Zhan, X.J., MenG, T., Zhang, S.N. \& WeI, F.W. (2010) Landscape features influence gene flow as measured by cost-distance and genetic analyses: a case study for giant pandas in the Daxiangling and Xiaoxiangling Mountains. BMC Genetics, 11, 72.

Zhu, L.F., Zhang, S.N., Gu, X.D. \& Wei, F.W. (2011) Significant genetic boundaries and spatial dynamics of giant pandas occupying fragmented habitat across southwest China. Molecular Ecology, 20, $1122-1132$.

\section{Biographical sketches}

CHeNG ZH A o studies the landscape ecology and conservation biology of the giant panda and the Sichuan sika deer. BISONG YUE works on the phylogeny of the sika deer and giant panda. JIANGHONG RAN is committed to giant panda conservation and the study of birds. Timothy Moermond works on bird behaviour and ecology. Ning Hou, XuYu Yang and Xiaodong Gu work on giant panda conservation. 